\title{
article
}

\section{The (in)adequacy of in-work benefits in Irish lone parent labour market activation policy}

\author{
Michelle Millar, michelle.millar@nuigalway.ie \\ NUI Galway, Ireland \\ Jane Gray, Jane.gray@nuim.ie \\ Maynooth University, Ireland \\ Clíona Rooney, cliona.rooney@nuigalway.ie \\ Rosemary Crosse, rosemary.crosse@nuigalway.ie \\ NUI Galway, Ireland
}

\begin{abstract}
In-work benefits (IWBs) are important in 'making work pay' for many low-income families. We consider the adequacy of Family Income Supplement (FIS) for Irish lone parents transitioning from social protection to paid employment. Drawing on interviews with lone parents and with stakeholders, FIS enables some lone parents to meet basic needs and move towards financial independence, there were also difficulties, and many are financially better off remaining on social protection. There is a need, either for significant changes or for the introduction of an alternative IWB to meet the requirements of lone parents transitioning from social protection to ensure that they are not living in poverty.
\end{abstract}

key words in-work benefits $\cdot$ lone parent employment $\cdot$ labour market activation $\cdot$ Ireland

To cite this article: Millar, M., Gray, J. and Rooney, C. (2018) The (in)adequacy of in-work benefits in Irish lone parent labour market activation policy, Journal of Poverty and Social Justice, vol 26, no 3, 379-400, DOI: 10.1332/175982718X15299561388618

\section{Introduction}

This paper examines the effectiveness of Ireland's in-work benefit (IWB), Family Income Supplement (FIS) ${ }^{1}$ in its current form to provide income adequacy for lone parents making the transition from social protection to paid employment. Our analysis takes place in the context of a significant policy change introduced in 2013, whereby the age threshold of the youngest child for receipt of the One Parent Family Payment (OFP) was reduced from 18 to 7. The OFP is a payment for those under 66 who are bringing children up without the support of a partner. Recipients must meet certain conditions and satisfy a means test. The OFP has an income disregard which allows recipients to earn up to $€ 130$ per week without an effect on payment. For some transitioning from OFP after their youngest child reaches 7 FIS enables lone 
parents to satisfy the mandatory work criteria while facilitating their caring duties, however, FIS in its current form is not suitable for all lone parents as the findings in this paper highlight. While the current system of Irish social protection has a number of means to support income adequacy for low income families this paper focuses specifically on FIS which is regarded as the primary IWB in Ireland. Drawing on data from two studies conducted by the authors (Millar and Crosse, 2016; Gray and Rooney, 2018), funded by the Department of Social Protection (DSP) and the Irish Research Council (IRC) we examine how effective FIS is as an IWB to ensure that lone parents in employment are not living in poverty.

We review the international literature on IWB's in labour market activation policies and discuss activation of lone parents in Ireland, including the significance of FIS in 'making work pay'. We then draw on interviews with lone parents in receipt of FIS and with stakeholders who engage with lone parents to highlight the benefits and challenges associated with the payment. While FIS enabled lone parents to meet basic needs and move towards a greater level of financial independence, there were also difficulties such as cumbersome paperwork, challenges arising from the annual review, stigma, a lack of awareness of FIS among some lone parents and the unsuitability of FIS for seasonal workers. However, stakeholders and some lone-parent recipients expressed an overriding concern that many lone parents are financially better off remaining on social protection.

While IWB's are crucial in 'making work pay' for lone parents transitioning to employment, only 6.9 per cent of those who transitioned since 2013 are in receipt of FIS (Houses of the Oireachtas, 2017). Of the approximately 25,500 recipients who exited OFP in 2015, 13,600 (54 per cent) moved to Jobseekers Transition Payment (JST) an out of work benefit for those with children aged 7 to 14,2,500 (10 per cent) to Jobseekers Allowance (JA) an out of work benefit for all unemployed individuals and 8,100 (32 per cent) to FIS (Indecon, 2017). A recent DSP commissioned survey reports that 53 per cent of lone parents surveyed reported being financially worse off since the reforms and 63 per cent of those in full-time employment cannot afford three or more items on the deprivation list (Indecon, 2017). In 2017, approximately 27,000 lone parents were in receipt of FIS (Indecon, 2017). Our analysis suggests some reasons why comparatively few lone parents have transitioned to FIS and indicates that there is a need, either for significant changes to the current system, or for the introduction of an alternative IWB to meet the requirements of lone parents transitioning from OFP to ensure that they are not living in poverty

\section{The role of in-work benefits in lone-parent labour market activation}

Welfare-to-work policies involve elements of compulsion and support to ensure that individuals make the transition to paid employment. Rowlingson and Millar (2002) identify three types of policies to support lone parents into employment: the introduction of strict work requirements or participation in activation programmes; changes to welfare payments and taxes to improve the financial incentive to work; and the provision of childcare services or subsidies. How each of these elements has been implemented varies from country to country. Financial supports and subsidies, such as grants, loans, tax credits and IWBs form an important element in supporting lone parents into employment (Rowlingson and Millar, 2002). IWBs are social protection 
payments for employees and are a core policy instrument in 'making work pay' for low-paid workers as opposed to being financially better off on social protection.

Research suggests that IWBs are a successful way to improve quality of life and reduce child poverty in lone-parent families (Brewer et al, 2012; Carnochan et al, 2005). Dale et al (2010) describe IWBs as politically attractive because they seem to fulfil both employment and distributional goals at the same time and take a variety of forms, such as tax credits, wage-related transfers or lump-sum payments; the choice of which to use will depend on the target group involved. Conventional IWBs are income tested, available to all workers on a low-income, and tend to have no time limit. Ray et al (2007) report on a qualitative evaluation of In-Work Credit (IWC). ${ }^{2}$ Lone parents interviewed were positive about IWC, using it for day-to-day living expenses. It was very important to those who had debts; high childcare, housing or transport costs; and those with low or unreliable incomes.

Casebourne et al (2010) explored the impact of the IWC on lone parents' retention and advancement in paid employment. Respondents reported IWC as being effective in supporting them by ensuring a reliable weekly income while they adapted to budgeting on a monthly wage and by offering additional income. Moreover, the expiration of their IWC payment did not lead to lone parents leaving employment: most were still in work three to seven months later, usually in the same job.

In relation to labour market activation tax credits have been introduced to make work more financially attractive than benefits and improve the income adequacy of low income families and therefore reduce poverty levels among the working poor. Canada, the UK and the USA have been at the forefront in the introduction of such tax measures where they are viewed as important policy instruments to make work pay. In recent years many countries have introduced tax credits as part of more widespread tax reforms including France, the Netherlands, Finland, Germany and Belgium. Much of this has been in response to the European Employment Strategy (2003) 'making work pay' guidelines (Verbist et al, 2007). Millar (2008) describes tax credits as a 'major innovation' in UK social protection policy by bringing the tax system directly into the role of assessing and delivering social protection bringing many more families into the domain of 'income-tested support'. Tax credits form a substantial addition to the wages of low-paid individuals and they make part-time work a financial option for many lone parents. Millar (2011) argues that a system based on a fixed tax credit payment for a set period of time would negate the difficulties families experience as it would provide stability and security of payment, but this would also remove flexibility to deal with changing circumstances.

A meta-analysis of 29 welfare reform initiatives in the US reports two primary findings: programmes that used mixed initial activities with a strong emphasis on employment had the best results, and only those programmes that included financial supports such as the Earned Income Tax Credit to those who entered employment led to increases in the income of participants (Bloom and Michalopoulos, 2001, cited in Carnochan et al, 2005). In Canada, the introduction of a wage subsidy for lone parents to take up full-time employment increased the length of time parents remained off social assistance and decreased the time spent on social assistance (Lacroix and Brouillette, 2011). In New Zealand, labour market activation policies have facilitated some to improve their income through paid work, but in a complex way. Income adequacy and security were not stable and engaging in paid work meant that lone parents were dependent on a combination of income sources. For most lone mothers, 
work alone did not pay; rather, the IWB, tax credits and child support, combined with wages, provided income adequacy (Patterson, 2008). Individual motivation to work among lone parents is related to the importance attached to caring as opposed to work and the problems anticipated in combining both (Breitkreuz et al, 2010; Haux, 2010; McMullin et al, 2002). Lone mothers place a high value on care, and their comprehension of what good mothering involves determines how they think about family life and employment (Manoogian et al, 2015; Henderson et al, 2005). IWBs have the potential to facilitate lone parents in combining paid employment with care by providing income adequacy.

\section{FIS and Lone parents Employment in Ireland}

In this section, we introduce the changes to social protection policy for Irish lone parents and present an overview of OFP, FIS and the Back to Work Family Dividend (BTWFD). The EU Survey on Income and Living Conditions (CSO, 2017) highlights that: lone-parent families continue to experience a disproportionate level of poverty with the rate of consistent poverty at 24.6 per cent for lone parents compared to 6.4 per cent for two-parent families, consistent poverty is experience by those who have an income of less than 60 per cent of the national median income and who cannot afford at least two of the 11 deprivation indicators. ${ }^{3}$ The 'at risk of poverty' rate was 40.2 per cent for lone parents compared to 12 per cent for two-parent families, that is, those who have an income of less than 60 per cent of the national median income. In relation to deprivation, for lone parents the rate was 50.1 per cent in 2016 compared to 6.4 per cent for two-parent families, material or enforced deprivation is measured by those who cannot afford two of the 11 deprivation indicators (CSO, 2017). Of all Irish lone parents, 40.8 per cent have very low-levels of education and have not completed secondary level education (CSO, 2012). As a result, those who are attached to the labour market tend to work in low-skilled areas with consequent low pay (Watson et al, 2011).

Lone parents in receipt of OFP constitute a comparatively small group in Irish society. Prior to the policy change, in 2010 there were 92,326 recipients of OFP, 49 per cent of whom were in paid employment and in receipt of an income disregard $(\mathrm{CSO}, 2012)$ at a time when there was an unemployment rate of 13.8 per cent. While proposals for lone-parent activation have been in the policy domain since 2006 (see Millar and Crosse, 2018), the decision to implement labour market activation for Irish lone parents was made in the context of commitments made under the Troika bailout (the three-year economic rescue programme implemented by the International Monetary Fund, the European Commission and the European Union (see Hick, 2018). The policy was framed in terms of savings to be made in the context of reforming social protection, moving from a contingency-structured regime to one that identifies claimants by reference to their relationship with the labour market. Claimants are simply young, old, or 'working age', resulting in an individualised social protection system with no reference to the caring obligations of lone parents.

These changes meant that the age threshold of the youngest child would be reduced from 18 to 7 over a phased period, those who no longer qualified for OFP would instead claim Jobseeker's Allowance (JA) and must be genuinely seeking work. Since 2012, 43,500 OFP recipients have exited the scheme. Those with children aged over 14 are required to be available and genuinely seeking full-time employment if they 
are in receipt of JA. However, those OFP recipients with children aged 7-14 are exempt from having to be available for full-time employment but they are obliged to engage with the DSP's activation services and receive a JST. Prior to the policy change under an earnings disregard scheme, those in receipt OFP could earn €147 per week and still qualify for the full rate of OFP payment. Half the remainder of gross earnings up to $€ 425$ per week was assessed as means. The reforms included a reduction in the earnings disregard for OFP from €147 per week to €90 in 2014 with the intention to reduce the disregard to $€ 60$ but this was reversed in 2017 when it was increased by $€ 20$ and again in 2018. There are differing options available for lone parents to combine social protection and earnings:

1. Those with children younger than 7 can combine OFP and the earnings disregard.

2. Those with children younger than 7 can combine OFP and FIS.

3. Those with children aged 7-14 can combine JST and the earnings disregard.

4. Those with children aged 14 and over can combine paid employment with FIS.

The most financially beneficial option is dependent on income thresholds, means, age of child and number of children in the family unit.

Those who were in employment and in receipt of OFP are entitled to apply for FIS and the BTWFD. The BTWFD is a time limited weekly payment for parents who move from social protection into employment or self-employment. For each qualified child (up to a maximum of four children), €29.80 is paid for the first year in employment. Half that amount will be paid in the second year (Millar and Crosse, 2016;2018). FIS is Ireland's IWB introduced in 1984 to compensate for the abolition of food subsidies, to preserve the incentive either to remain in employment or to 'move from welfare dependence to employment', and to provide a temporary solution to low-income pending the reform of child income support. However, such planned reform did not transpire and FIS has remained as a targeted support for low-income families (DSP, 2010,39). When FIS was introduced, fewer than 10 per cent of families in Ireland were headed by lone parents (Fahey and Field, 2008, 42), compared to 18 per cent of family units in 2016 (CSO, 2017,38). This was at a time when there was no requirement on lone parents in receipt of social protection to be in employment. However, in 2014, lone parents accounted for almost half of all families in receipt of FIS as is evident in Figure 1.

FIS is a weekly tax-free payment for all families, where one or both parents are working a minimum of 38 hours over a two-week period, and where earnings are less than specific limits set for family size. FIS payments are a minimum of $€ 20$ per week and a maximum of 60 per cent of the difference between the family's average weekly income and the limit. Table 1 is an example taken from the DSP website of a FIS calculation (see Table 1).

Murphy (2012) argues that FIS might not be suitable for all individuals, particularly those in precarious employment. Irish women are more likely to work in low-paid, part-time precarious work. Precarious hours and short-term seasonal contracts are prevalent in sectors such as tourism or retail (Murphy,2012) and many lone parents opt to work in these sectors (McGinnity et al, 2014, 41) as local employment is necessary for them to fulfil their roles as carer and earner. FIS payments are calculated annually and if a recipient has their wages or their hours of work reduced during the year, their FIS payment will remain the same until the next review. However, if the hours 
Figure 1: Number of one and two parent families receiving FIS in Ireland, 2003-2014 30,000

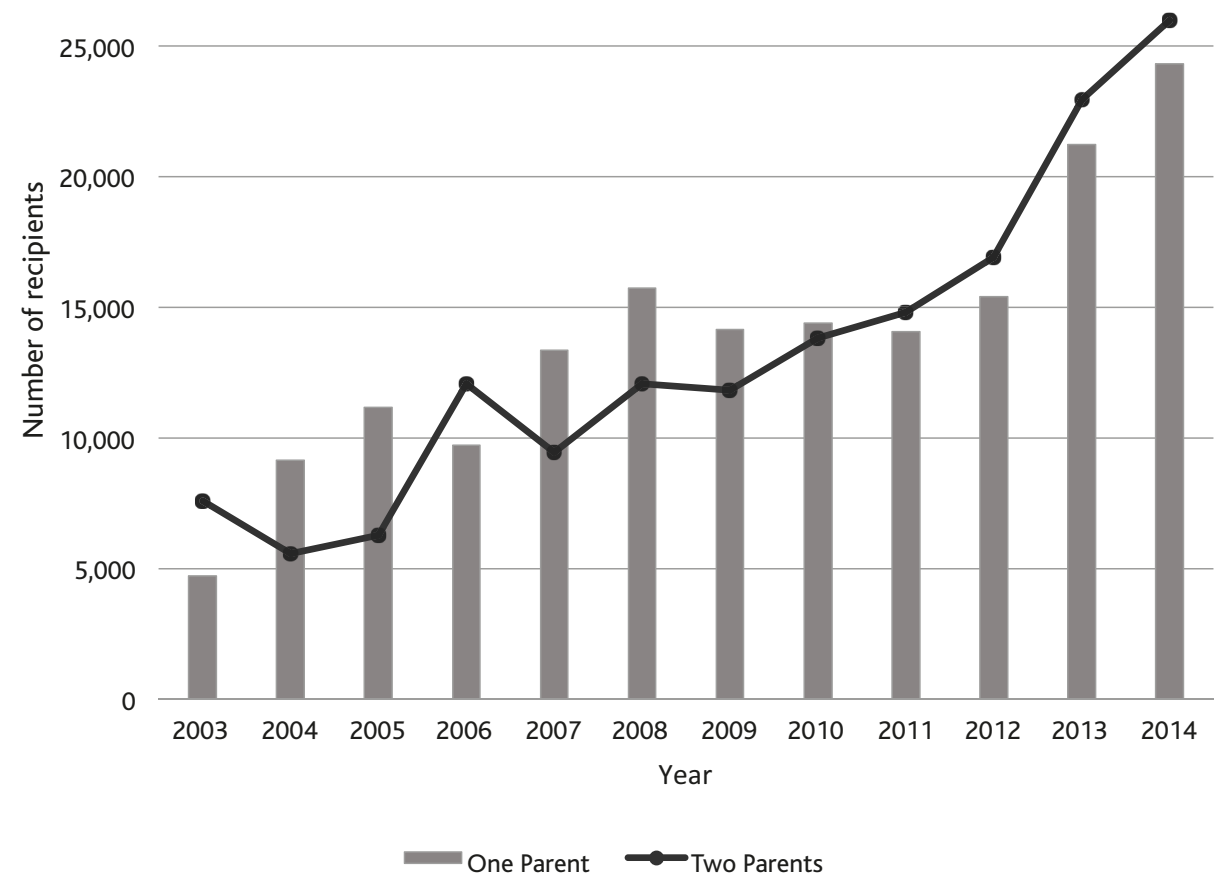

Note: Available at www.welfare.ie/en/Pages/Annual-SWS-Statistical-Information-Report-2015.aspx.

Source: Department of Social Protection Annual Statistical Information Reports.1 (DSP, 2017)

Table 1: FIS payment for lone-parent, 1 child, recently commenced working 25 hours per week

\begin{tabular}{|l|l|}
\hline Gross taxable earnings to date & $€ 360.00$ \\
\hline Total tax deducted & $€ 0.00$ \\
\hline Employee Pay Related Social Insurance & $€ 14.40$ \\
\hline Total Universal Social Charge & $€ 10.54$ \\
\hline Net assessable earnings & $€ 335.06$ \\
\hline Number of weeks worked & 1 \\
\hline Average weekly earnings & $€ 335.06$ \\
\hline Other Income & $€ 0.00$ \\
\hline Total family income & $€ 335.06$ \\
\hline Income limit (1 Child) & $€ 511.00$ \\
\hline Difference between income limit and earnings & $€ 175.94$ \\
\hline FIS Payable (60\% of difference rounded) & $€ 106.00$ \\
\hline
\end{tabular}


worked fall below the FIS threshold of 38 hours per fortnight or if their employment ceases, they are no longer entitled to FIS and the payment ends. Furthermore, those returning to employment on a contract without fixed hours may be unable to provide proof of working 19 hours a week to qualify for FIS. It is argued that there is low take-up of FIS by eligible families, with some estimates that only 40 per cent of those eligible are in receipt of FIS (ECPC, 2013; Savage et al, 2017).

Since 2015, advocacy and support groups raised concern that many lone parents would be financially worse off due to their move from OFP to JA and FIS. Single Parents Acting for the Rights of Our Kids (SPARK) and One Family presented concerns to the Joint Committee on Education and Social Protection of the Houses of the Oireachtas in February 2015. SPARK reported that lone parents moving to FIS will lose their fuel allowance of $€ 520$ annually and 40 per cent of their current OFP as a result of the policy change to the OFP (Bayliss, Oireachtas Debates, 18/02/2015). In 2017, SPARK reported to the Joint Oireachtas Committee on Social Protection (JOCSP) that a lone parent earning $€ 210$ with one child and receiving $€ 75$ maintenance will be over $€ 50$ per week better off if they come off FIS and return to JST (Houses of the Oireachtas, 2017,38). An example of the impact of the reform on a lone parent who had been working part time, in receipt of both OFP and FIS is presented in Table 2, the lone parent has been moved from OFP and FIS, to FIS alone which has resulted in a reduction of $€ 41.20$ a week including the fuel allowance.

Table 2: Impact of the OFP Reform on a lone-parent working part-time

\begin{tabular}{|l|l|l|l|}
\hline Income Before OFP Reform & $€$ & Income After OFP Reform & $€$ \\
\hline OFP & 182.00 & OFP & 0.00 \\
\hline Earned income & 173.00 & Earned income & 173.00 \\
\hline FIS & 91.00 & FIS & 202.00 \\
\hline Maintenance & 0.00 & Maintenance & 0.00 \\
\hline BTFWD & - & BTFWD & 29.80 \\
\hline Fuel allowance & 20.00 & Fuel allowance & 0.00 \\
\hline Total & 466.60 & Total & 404.80 \\
\hline
\end{tabular}

Source: One Family, 2015

The JOCSP reported that since 2012, 43,500 parents exited the OPF scheme and 3,000 lone parents became new FIS recipients by the end of 2015 (Houses of the Oireachtas, 2017,38). While this figure does not explain the situation in its entirety this means that only 6.9 per cent of those who transitioned were moved to the IWB:

The small proportion of the total accounted for here may be the beginning of a trend whereby lone parents are transitioning into employment having left the scheme or, it may be a reflection of improved economic circumstances in general. Whatever the reason it seems obvious that further evidence needs to be gathered before the outcome of the changes can be seen. (Houses of the Oireachtas, 2017, 38) 
Considering the poverty statistics in relation to lone parents, however, it is doubtful that they are experiencing 'improved economic circumstances'. Data from the report commissioned by the DSP highlight that 48 per cent of individuals who exited OFP in 2015 had their income reduced.Those who exited in 2016 had their income remain the same and the authors suggest that this may be due to differences between the 2015 and 2016 groups such as parental age and age of children. They conclude that 'it is too early to make definitive conclusions on the impact of the policy changes in incomes in the medium term' (Indecon, 2017, 56). However, they report that for all those who have exited OFP 53 per cent of lone parents reported being financially worse off since the reforms and 63 per cent of those in full-time employment cannot afford three or more items on the deprivation list (Indecon, 2017). These employed lone parents are experiencing 'in-work' poverty and daily deprivation.

\section{Findings}

As stated above, the findings in this paper draw from two studies funded by the DSP and IRC. The first study (Millar and Crosse, 2016) hereafter referred to as the 'Activation and Inclusion Study' (AIS) is based on research commissioned by the Social Inclusion Division in the DSP in November 2014 and was funded by the IRC. The data utilised in AIS was collected from 20 semi-structured qualitative interviews with policy actors, organisations representing those parenting alone, community and voluntary organisations working with those parenting alone and state bodies involved in the activation of lone parents and focused on capturing the participants' knowledge and expertise regarding activation of lone parents, as well as their views on what activation measures and supports work best for lone parents in the Irish context. By engaging with organisations that work with lone parents, the research is grounded in tangible evidence from those with the knowledge and expertise to consider activation in the Irish context.

The second study (Gray and Rooney, 2018), hereafter referred to as the 'Enabling Resilience Study' (ERS), investigated the experiences of low-income families receiving FIS. This study was funded by the IRC in collaboration with the DSP. The present analysis is based on the subset of participants in ERS who are lone parents. Overall 30 parents and guardians receiving FIS were biographically interviewed of whom 13 were lone parents. Participants were living in the Midlands Region of Ireland, which experienced considerable population growth during Ireland's economic boom and subsequent high increases in rates of unemployment and mortgage arrears following Ireland's financial crisis. Interviews were analysed using thematic framework analysis. Ethical approval for ERS was granted by the Maynooth University Ethics Committee. The analysis here centres on the experiences of the 13 lone parent respondents in ERS. These participants were aged 35 to 67 years, and most were Irish (two were from other European states). Two received both FIS and OFP as they have children aged less than 7 years. One was a voluntary guardian and 11 had previously received OFP when their children were aged less than 7.

Data from both studies were combined using qualitative synthesis, which is used to amalgamate a body of research about a topic (Hannes and Lockwood, 2012; Ring, et al, 2010).A variation of meta-ethnography developed by Noblit and Hare (1988) was used to compare, analyse and further interpret results. Overarching themes were used to establish differences and similarities that existed between both datasets. We followed 
seven steps as outlined by Noblit and Hare (1988) to establish an overall picture of FIS from both the experiences of FIS recipients (ERS) and key stakeholders (AIS) (Table 3). The first four steps focus on selecting and determining appropriate studies. Steps five to seven focus on translating, synthesising and reporting data from both studies.

Table 3: Seven steps of meta-ethnography

\begin{tabular}{|l|l|}
\hline Steps & Description \\
\hline Getting started & \multicolumn{2}{|l|}{} \\
\hline Deciding what is relevant to the initial interest & Selecting appropriate studies \\
\hline Reading the studies & Reviewing the studies \\
\hline Determining how the studies are related & Searching for common concepts between studies \\
\hline Translating the studies into one another & Creating a grid to compare studies \\
\hline Synthesising translations & Developing a relationship between concepts \\
\hline Expressing the synthesis & Reporting the synthesis \\
\hline
\end{tabular}

Source: Adapted from Noblit and Hare, 1988

Table 4: Super ordinate and sub-themes

\begin{tabular}{|l|l|l|}
\hline Core theme & Theme & Sub-theme \\
\hline Favourable aspects & Dignity & Meeting basic needs \\
\hline & & Financial independence \\
\hline Negative experiences & Rules pertaining to FIS payments & Less stigma \\
\hline & & $\begin{array}{l}\text { Lownual review of FIS } \\
\text { working arrangements }\end{array}$ \\
\hline & & Employer's role in FIS process \\
\hline Thoughts on FIS & & Changes in income \\
\hline & & $\begin{array}{l}\text { FIS as a stepping stone/part of a package } \\
\text { of support }\end{array}$ \\
\hline
\end{tabular}

\section{Favourable aspects of FIS}

In this section, the findings from the two studies funded by DSP and IRC are presented. Findings are conceptualised into three core themes (Table 4). Lone parents in ERS described the positive aspects of receiving IWBs and explained how FIS enabled them to meet basic needs and move towards a greater level of financial independence. Participants described the importance of IWBs to working lone parents in enabling them to meet their basic needs:

I wouldn't be as comfortable as I am without my social welfare payments because...the majority of my wages goes on my rent...so the balance that is left over from both my payments (BTWFD and FIS) would be for my bills and shopping. (Caitriona) 
Participants noted that while payments are small they go towards the purchase of food or products that benefited their children. Recipients described the contrast between struggling to make ends meet before and after they received FIS:

It was like somebody taking a big weight off my shoulders...I remember going in and filling the fridge full of food and buying the kids' clothes. (Edel)

Some participants described living in substandard conditions and receiving food from employers prior to applying for FIS. Others asserted that FIS enabled them to live week-to-week. FIS was highlighted as an incentive for part-time workers such as Aisling who would be unable to work part time without FIS, due to the cost of commuting. It also afforded her the opportunity to progress in her career:

FIS really makes a huge difference... when you are not as stressed about money...you start to think more about your career. (Aisling)

For those whose children required childminding, FIS enabled them to work part time and care for their families outside of school hours. Some parents had been financially reliant on partners prior to separation and FIS enabled them to start working for the first time in years and become financially independent.

My husband would have paid for everything, he organised mortgage, car insurance holidays, everything...I went to my employer...he would have known the situation I was in then...I was saying to him 'You know if fulltime work is available I'll come and work full-time.' (Catriona)

The lone parents appreciated that FIS is paid weekly and maintained that it provided them with a sense of security:

FIS is so important because you know that...that money is going to be there every Thursday, at least there is that. (Denise)

Lone parents in ERS felt that there is less stigma associated with receiving FIS as opposed to other social protection payments as FIS is processed by direct debit rather than being collected in person at the post office:

FIS means a huge amount to me. It allowed me to keep my dignity because... nobody knows I'm getting FIS. (Christina)

However, while FIS was viewed as a more private payment than JA, some parents still associated FIS with social stigma. Parents expressed a desire to leave social welfare protection and some therefore delayed entering the FIS system. In Orla's case she was originally working part time and although she was earning low wages, she felt uncomfortable about applying for state assistance:

I kind of didn't want to depend too much on social welfare and I never really bothered looking into FIS. (Orla) 


\section{Negative aspects of FIS}

Several negative issues associated with the FIS payment emerged from the ERS interviews with lone parents: the annual review of the payment; the issue of non-fixed and low-hour contracts; precarious working arrangements; loss of income as result of lone-parent activation, as well as the employer's role in securing FIS. The annual renewal process was a considerable issue for interviewees in ERS. This was particularly so for participants whose wages were reduced and in the case of an interviewee who had received a one-off work bonus payment before her annual re-assessment. Once recipients are accepted for FIS, their payment continues for 52 weeks. FIS payments are not affected by increasing or decreasing wages until the annual review, whereby a recipient can re-apply giving details of their new reduced income. At the end of the 52-week period, a recipient can re-apply for next year. However, payments are affected if recipients lose their job, their hours are reduced below the minimum 38 hours per fortnight, they have another child during the year, or their OFP ceased due to the age of their youngest child. If they lose their job they are no longer entitled to FIS and in both cases the DSP must be notified immediately.

In the case of the lone-parent activation policy, however, the DSP decided that lone parents moving off OFP did not have to wait the required 52 weeks for their FIS payments to be reviewed to take account of the changes as explained by a policymaker in AIS:

Usually FIS is reviewed annually, and it's set in stone so irrespective of your personal circumstances with the exception of a new child your FIS payment isn't adjusted. So, in 2013 we changed that for lone parents who were affected specifically by this transition so that FIS, even though it's not their annual review, will be automatically increased to take account of 60 per cent of the loss of their OFP. Now what that means overall is they're still down because they're going to lose 40 per cent of OFP but without that they will have lost 100 per cent of OFP. (Policymaker 1)

Lone parents in ERS also discussed the impact of the 52-week renewal feature of FIS on their lives. Orla and Denise who have mandatory unpaid leave each year, found this aspect punitive for them. Orla is a seasonal worker employed from March to November. Denise is required by her employer to take three weeks unpaid leave each year and then collects JA for three weeks. Therefore, she must cancel and reapply for FIS each year, resulting in a period where does not receive a wage or a social protection payment resulting in misalignments between payments each year:

The mess up when...every year there is a recurring lay off. To at least be sure while they are sorting out the bank, the JA, that at least leave you that. Do you know? But as soon as they start to process your claim they stop, the FIS stops. Then you have nothing and then you must get the JA and then... there is nothing coming in, then I go back to work we'll get paid... we'll get one-week's wages when we go back to work, and the JA will probably come through then and then you have to go back and reapply for FIS. (Denise) 
In line with this, lone parents whose circumstances changed were required to wait until the end of their FIS year to have their claim reassessed. Sandra felt that this aspect of FIS should be readdressed:

I think really if your circumstances change, that should be taken into account. (Sandra)

The fact that reviews are conducted annually, however, can work to the benefit of those recipients whose income has increased as their FIS payment won't be cut until the next review.

Many parents suggested that there were challenges associated with filling out paperwork. Often participants filled out similar forms for more than one social welfare payment. Margaret noted that she was asked to send the same documents to the department on more than one occasion. Aisling found the process frustrating:

It's frustrating when it comes to all the information that they are looking for. It's all repeated information. (Aisling)

To qualify for FIS payment a recipient must work 38 or more hours per fortnight (or 19 hours per week). If the number of weekly hours worked by a recipient is reduced to below 38 hours per fortnight they are no longer entitled to FIS. The lack of flexibility on the hour's criteria can be an issue for some lone parents. Respondents in AIS also highlighted the challenges associate with meeting the criterion for number of hours:

A flexibility around the 19 hours; if your job will only give you 16 hours; you've obviously shown your willingness to activate, you know. (Activist 1)

For others, the lack of flexibility in the hour's criteria is not conducive to real life circumstances and is restraining as one stakeholder in AIS explains:

You're not entitled to FIS because you're not doing 19 hours; you're only doing 15 hours. They're putting ridiculous restraints on people, ridiculous; that are not realistic. You have to look at each case in and of its own and look at how you can flex things to support that family.You can't just stick a framework onto people, life isn't like that. (Voluntary Sector 1)

In a similar vein, the reality of trying to secure 19 hours was highlighted by other respondents in AIS as an issue, with the point being that it is difficult to demand 19 hours from any employer:

We're aware people don't have the 19 hours and they're not making it to the FIS, the eligibility for that has to change. Why not encourage them to take the 10 hours, take the 8 hours? Take them; we'll give you part-time scheme. Just take something to get yourself moving... That 19-hours FIS I think, this criteria has to change; it has to match where people are, it has to match the economy...it's not within the gift of an employee to demand 19 hours. (Activist 2) 
The issue of the qualifying criteria for receipt of FIS is further exacerbated by the prevalence of 'if and when' and other precarious contracts. There is no guarantee of securing the consistent 19 hours per week required to qualify for and maintain the FIS payment while on this type of contract. While those in the policy arena accept that this is a problem, and maintain that work is ongoing to address it, they believe that there is a limit to what can be achieved, as explained by one policy actor in AIS:

I'm surprised on a personal level zero-hour contracts haven't been a much bigger issue over recent years... But at the end of the day we won't be able to force an employer to increase hours. We're definitely trying to make them aware just how beneficial getting up to 19 hours is... Most employers are reasonable, and they'll assist their employees if needs be. (Policymaker1)

Other respondents in AIS suggested that employers should be more aware of the circumstances of employees in this situation:

There's a major piece of work to be done with the employer on understanding social welfare because that's not the remit of an employer. An employer is offering hours and he's not responsible for how you're treated or affected by social welfare....to explain to them 'Well, if you gave Barbra 19 hours you're actually increasing her salary by this.' (Advocate 2)

When discussing precarious contracts, respondents in ERS questioned the 19-hours' threshold and maintained that it was difficult for some lone parents to obtain enough work to qualify for FIS. Aisling described how she was offered a job with a low-hour contract after losing her job. It was not possible for her to accept employment for four hours a day due to the cost of commuting:

You do four-hour shifts... which would not suit me at all...I was thinking of the travelling. (Aisling)

In relation to the hour's threshold, retail workers such as Vika in ERS noted that it was difficult to predict her hours. Therefore, she was unsure if she would qualify for FIS next year:

I have trouble working out what I have because my hours is different from one week...I have one week 15 , second one is 30 , then I have a 14 you know?...I know that the FIS is supposed to be...19 hours... but I sometimes I don't have that. (Vika)

In AIS two specific issues were raised in relation to the employer's role in securing a FIS payment for an employee. The first relates to privacy. The fact that employers must sign off on a FIS application means that they are aware of their employee's need for a DSP payment, which may be a contentious issue for the employee, due to the lack of privacy around their personal circumstances. The second issue concerns the burden on the employer due to the necessity for paperwork. This is something that those in the policy arena are aware of as highlighted by policy actors in AIS: 
A key issue is people (a) don't want their employers to know that they need social welfare support or (b) are afraid to go to the employers and say 'Fill out this form' and employers are saying 'Not another bloody form', you know. (Policymaker 1)

Those who advocate on behalf of lone parents also highlighted this issue. The amount of paperwork for the employer has increased due to the necessity for accompanying letters to be included with the application.

I've heard a lot of people saying, a lot of people who have increased their hours to the 19 hours, firstly they had to sign section 8 of the FIS form and your employer has to sign it. There are a few cases I know now, the employer has signed that, the form has gone in and FIS was refused because well we needed a letter as well. So now to get FIS you now need to fill in the section 8 and the employer has to send a letter as well. (Advocate 1)

Moreover, as stakeholders in AIS explain the requirement of an employer to fill out forms for social protection payments puts recipients in a weaker position in terms of being able to secure and maintain jobs. Due to the inconvenience of the paperwork involved, it might be easier for employers to employ those with no such requirements:

It's bureaucratic and it's also putting up a barrier because an employer has a worker who doesn't need all this signed or one who has to get all these forms signed. (Advocate 1)

There is a significant concern that the transition from OFP to FIS has resulted in a reduction in income for some, particularly those who were already in employment. In AIS those in the policy arena acknowledge such losses:

The big area to come up is those already in employment and the impact the reform is going to have on them moving off OFP. Depending on the circumstances but yes there can be losses. Some of those losses can be significant per week. (Policymaker1)

Other policymakers while acknowledging possible income losses expressed the view that such losses are marginal and could be remedied by increasing hours of work:

I suppose some people are going to fall through the cracks. But I know that the jobseeker payments teams and the FIS teams are looking at it...but I suppose there will be some people who would lose out marginally. I think they're saying to those people you can increase your hours slightly and still get your FIS, where feasible. (Policymaker 2)

Lone-parent advocates in AIS are of the view that losses in income because of activation were substantial and particularly more so when entitlement to the BTWFD runs out, following the lone parents' second year of employment: 
The first thing is the loss of income; a minimum wage worker working 19 hours a week will be down $€ 78$ a week by July and that'll rise to $€ 108$ by the time they lose BTWFD, so €108 a week on a lone parent working 19 hours. That's obviously not viable. It's that shocking, its $€ 108$ for somebody working 19 hours, doing everything the Department has said, working the hours to get FIS, one child and they're going to be down €108. (Advocate 2)

Going on to explain the details of such losses, advocacy groups maintain that changes to income disregard since 2012, the fact that FIS only replaces 60 per cent of OFP, loss of fuel allowance because of uptake of FIS and eventual loss of the BTWFD all culminate in the loss of $€ 108$ per week for some lone parents:

The income disregard means every working lone parent who earned over $€ 90$ has lost $€ 28$ because of income disregard, going from $€ 147.60$ to $€ 90$. That was $€ 57.60$ divide by two is your $€ 28$... So, we've all lost that cumulatively since 2012. Then it's $€ 50$ a working lone parent on minimum wage loses because if you look at the way FIS and OFP, FIS replaces 60 per cent of your OFP.The perverse thing about that is those earning less needed OFP more, would have had a high OFP so for them to lose 40 per cent of OFP, they're the poorest...It's the perverse thing about these changes; that the lower you earned the worse you're affected. Fuel allowance as well, because on OFP you were allowed fuel allowance and you're not allowed it on FIS...getting the $€ 29.80$ BTWFD but you're losing $€ 10$ a week from the fuel allowance anyway so it's still only, €20. (Activist 2)

Lone-parent interviewees in ERS described how they suffered from a loss of income following the transition from OFP to FIS. Orla described the impact of transition on her life:

OFP would have been slashed or stopped because of John being a certain age...I was down something like $€ 75$ a-week which is huge. (Orla)

Orla lost her entitlement to fuel allowance after the transition which affected her as a seasonal worker, as she is unemployed during the winter. She felt misled and suggested that working lone parents were disadvantaged by changes to OFP:

You know, and you are allocated a fuel allowance. When I was on OFP it was automatic and that was $€ 20$ a week... But that stopped when OFP stopped or whatever system I went on...they wouldn't allow fuel allowance.

Margaret believed that removing OFP, once a recipient's child reached 7 years of age, should be reviewed. She maintained that the financial costs associated with raising a child over the age of 7 are high:

I find it harder, there is more demands, he needs more stuff and like he's in national school now. (Margaret) 
While we have seen the potential of the changes to OFP to result in significant losses in income, it is worth noting that those in the policy arena are of the view that there have been significant gains in income because of lone parents transitioning to the FIS payment:

If someone wasn't on FIS and goes from OFP and claims FIS and BTWFD the increases can be very, very significant. If they are working or they can get up to 19 hours, it's so much more financially beneficial for them. (Policymaker 1)

In the ERS study, some parents who transitioned from OPF to FIS found that there was financially little difference between both payments:

I didn't see any difference. Except for the name and I don't understand why they did it. (Margaret)

It had a profoundly negative impact for Áine, however. Her payment was reduced following the transition and she was anxious about paying bills:

Last year my son was 7 so I lost my OFP which [meant] I was down $€ 160$ a week. So, the way I was led to believe that no one was going to be down anything...just...FIS took it over and gave you the difference. That's what I was led to believe; it was not like that at all. (Áine)

FIS was viewed as a stepping-stone to a full transition from welfare to work by those in the policy arena. Policy actors in AIS explain:

Ideally you want people [getting] into very well-paid employment but it's going to be a long process for a lot of these individuals and you have to be realistic about that as well. Financially the best thing for a working lone parent if they're in receipt of OFP is to get on FIS and that's the message we're pushing. Now do we want them to be on FIS forever? Absolutely not, we want them to get a better job, better paid job that gets them out of welfare. But it's definitely a step in the right direction. (Policymaker 1)

FIS is only one part of a package of supports that the DSP has put together to support people to take up employment, such as BTWFD and the Housing Assistance Payment (HAP).A civil servant in the DSP stated that although FIS is supportive, it is not perfect:

We will support the employee, through FIS, BTWFD; hopefully HAP if they're in receipt of HAP and the medical card. That's a strong package and it addresses a lot of the big fears people have. Now is it complete? No. And can it be improved on? Yes. But it is there as a basis for us into the future. I think what'll happen is probably hopefully as the economy continues to pick up and our jobseekers numbers decline we'll be left with a group of jobseekers and we'll be able to probably tailor supports to the harder to move. (Policymaker 2) 


\section{Discussion}

In line with other countries, Ireland has been moving away from a breadwinner model of labour market participation to a dual-earner model. Especially in the context of reforms introduced under the Troika, state support for labour market participation has shifted to an adult worker model, with notable consequences for lone parents, who previously were not subjected to labour activation measures. This paper makes a significant contribution to the research area of lone-parent activation and the utilisation of IWBs in that process. International research suggests that there are a wide variety of IWBs available in other jurisdictions, some of which have been shown to be successful in providing income adequacy to lone-parent recipients (Ray et al, 2007; Casebourne et al, 2010). In many countries 'making work pay' policies have contributed to an increase in employment and a reduction in poverty in loneparent families (Verbist et al, 2007). While findings from this study show that, in some instances, FIS is effective in assisting lone-parent recipients to meet basic needs, key issues remain both in relation to the success of FIS as an activation support and in its application. Such issues raise questions about the capacity of FIS in its current form to provide income adequacy for many lone parents in Ireland.

It has been argued that FIS, as it currently operates, might not be suitable for all individuals returning to employment, particularly those in precarious employment (Murphy, 2012). Many lone parents are in low-paid, low-skilled and part-time precarious employment (Watson et al, 2011; Murphy, 2012) in the retail and tourism sectors as local employment is necessary for them to fulfil their roles as carer and earner. Findings from this study provide some support for these assertions. Several lone parents interviewed for ERS are engaged in precarious employment characterised by seasonal work, or by temporary or low-hour contracts. Lone parents describe working in roles with no specified hours of work, and no guarantee of the consistent 19 hours of work per week required to meet the qualifying criteria for FIS. These types of working environments can lead to precarious conditions, as described by lone parents in ERS, such as unstable income, along with difficulties managing work and family life. Such employer's practices are questionable, however, stakeholders in AIS contend that this is a difficult issue to resolve as the onus is on employers to set hours of work. While there are plans to implement legislation to regulate precarious employment, the impact of these measures remains uncertain. Furthermore, seasonal employment runs contrary to the intentions of FIS, which aims to promote stable and continuous employment.

The initial intention of the introduction of FIS as an IWB in Ireland was to provide a temporary solution to low income among families with children. While the findings from this qualitative study are limited and do not purport to be the case for all lone parents, in the context of more vigorous measures to activate labour market participation, moving lone parents from OFP to JA and FIS has resulted in some of them being financially worse off. Lone-parent advocacy groups have presented evidence to the Houses of the Oireachtas that the cumulative effects of the changes have resulted in reductions in income for many who have transitioned to FIS (Bayliss, Oireachtas Debates, 18/02/2015). The experiences of many lone parents in ERS are consistent with these assertions, with participants highlighting a range of reductions in income. Such losses were also recognised by expert informants within the policy 
arena in AIS, who acknowledged 'significant losses' per week among those who were already on limited hours of employment prior to the policy change.

As outlined earlier in this paper, evidence from other jurisdictions shows that tax credits and IWBs are significant in assisting with the transition from welfare to work. Overall, the research suggests that IWBs are a successful way to improve quality of life and reduce child poverty in lone-parent families (Brewer et al, 2012; Carnochan et al, 2005). This study provides a collation of evidence from two studies funded by the DSP and the IRC examining both what works in lone-parent activation and the experiences of low-income families in receipt of FIS. While the evidence suggests that FIS acts as a valuable support for employment among some lone parents, there are also difficulties with FIS as an IWB. These include: challenges arising from the yearly review and the employer's role in the process. However, it is the lack of capacity of the payment to deal with issues of precarious employment and reductions in income that are of fundamental concern to some lone parents.

In line with the adult 'making work pay' philosophy, policy actors in this study express the view that FIS is a stepping stone to a full transition from welfare to work. As stated previously, Irish lone parents have low levels of educational attainment and those who are attached to the labour market tend to work in low-skilled areas with consequent low pay. These features, combined with caring responsibilities which preclude many from engaging in full-time employment, have resulted in lone parents continuing to have a higher risk of poverty and deprivation than that of the general population. Therefore, it is doubtful that a 'making work pay' approach which utilises FIS as an IWB to increase the labour force participation of lone parents without addressing the quality of employment or reductions in income evidenced in this study will be effective. Our findings therefore encourage a rethinking of the current system, which requires either significant changes or the introduction of a modified IWB system.

This leads us to question how policy-makers can resolve the negative aspects associated with FIS. Issues such as proving hours worked, employer power and the annual review could be negated by the proposed reform for the Office of the Revenue Commissioners to collect real-time information from employers regarding earnings and possibly hours worked for all employees which would allow for the automatic award of in-work benefits (Savage et al, 2017). One Family (2017) recommend lowering the 19 the hours limit to 15 in recognition of the difficulties lone parents face in balancing work and care. However, this could result in employers responding in lowering the hours of work they offer to FIS recipients, not all of whom might wish to have their hours reduced. Alternatively, a move towards the introduction of a tax credit system would provide a stable and secure payment for all lone parents in employment and if real-time information on earnings is available it would negate the issue of hours worked as required by FIS. The effectiveness of such a system would, however, be dependent on real-time information on earnings being available and the flexibility of the DSP to respond to changes in earnings in a timely manner so as not have those in receipt of a tax credit under- or overpaid for an unreasonable length of time. 


\section{Conclusion}

Lone-parent activation in Ireland has been postulated as a solution to high poverty rates experienced by these families. While the international literature does suggest that IWBs can assist lone parents in making the transition to work as part of an activation policy and are a successful way of improving quality of life and reducing child poverty in lone-parent families, data from the two studies brought together in this paper, together with official statistics on the uptake of FIS by activated lone parents show that Ireland's IWB does not work for all in its current form. Participants in these studies describe situations where lone parents are financially less well-off because of being in employment and receiving FIS, as opposed to OFP.While policy actors acknowledge significant losses in income in some cases, FIS is still regarded as financially the best support for a working lone parent.

FIS can support lone parents through the initial move from benefits to employment by ensuring a reliable weekly income while adapting to budgeting on a wage and by offering additional income. However, FIS was designed 33 years ago as an IWB for low-income families, with two parents in mind, at a time when there was no work requirement on lone parents in receipt of social protection. The capacity of a lone parent to work and care cannot be compared to that of a two-parent family and, as such, an IWB designed with two parents in mind requires modification. FIS has the potential to protect lone parents from a loss of income. Removing or creating flexibility in relation to the hours requirement for a limited period (at a minimum) would enable lone parents to make the transition to employment as it would facilitate part-time and seasonal employment, create income adequacy and encourage work-family balance.

\section{Notes}

${ }^{1}$ FIS was renamed the Working Family Payment in January 2018.

2 The IWC is a non-conventional IWB, as it was aimed specifically at lone parents, it had a 12-month time limit, and entitlement was conditional on previous receipt of welfare (Brewer et al, 2012). The IWC is no longer available.

3 The 11 deprivation indictors are two pairs of strong shoes, a warm waterproof overcoat, buy new not second-hand clothes, eat meals with meat, chicken, fish or vegetarian equivalent every second day, have a roast joint or its equivalent once a week, had to go without heating during the last year through lack of money, keeps the home adequately warm, buy presents for family or friends at least once a year, replace any worn out furniture, have family or friends for a drink or meal once a month, have a morning, afternoon or evening out in the last fortnight for entertainment.

\section{Funding information}

Irish Research Council

(Department of Social Protection Research Innovation Award 2014)

Dr Michelle Millar

Irish Research Council

(Department of Social Protection under the Research for Policy and Society Programme, 2015)

Dr Jane Gray 


\section{References}

Bayliss, L, 2015, Joint Committee on Education and Social Protection Debate, 18 February, http://oireachtasdebates.oireachtas.ie/Debates\%20Authoring/DebatesWebPack. nsf/committeetakes/EDJ2015021800002?opendocument\#K00100

Breitkreuz, RS, Williamson, DL, Raine, KD, 2010, Dis-integrated policy: welfare-towork participants experiences of integrating paid work and unpaid family work, Community, Work and Family, 13, 1, 33-69

Breitkreuz, RS, Williamson, DL, 2012 The self-sufficiency trap:A critical examination of welfare-to-work, Social Service Review 86, 4, 600-689

Brewer, M, Browne, J, Chowdry, H, Crawford, C, 2012, The impact of a time-limited, targeted in-work benefit in the medium-term: An evaluation of In Work Credit, ISER Working Paper Series, Issue 2012-04

Carnochan, S, Ketch,V,De Marco, A, Taylor, S, Abramson, A,Austi, MJ, 2005, Assessing the initial impact of welfare reform, The Social Policy Journal 4, 1, 3-31

Casebourne, J, Bell, L, Davies, M, 2010, Supporting Lone Parents' Journey off Benefits and into Work: A Qualitative Evaluation of the Role of In Work Credit, Sheffield:Department for Work \& Pensions

CSO (Central Statistics Office), 2017, Survey on Income and Living Conditions 2016, Dublin: CSO.

CSO (Central Statistics Office), 2012, Census 2011 Statistics on Lone-parent Families, Dublin: CSO

Dale, MC, Wynd, D, St John, S, O’Brien, M, 2010, What Work Counts? Work Incentives and Sole Parent Families, Rugby: Child Poverty Action Group

DSP (Department of Social Protection), 2010, A Policy and Value for Money Review of Child Income Support and Associated Spending Programmes, Dublin: DSP

DSP (Department of Social Protection), 2014, Statistical Information on Social Welfare Services 2013, Dublin: DSP

DSP (Department of Social Protection), 2018, Working Family Payment examples, www.welfare.ie/en/Pages/WorkingFamilyPayment-Examples.aspx

ECPC (End Child Poverty Coalition), 2013, Position Paper on Reforming Child Income Supports, Dublin: ECPC.

Fahey, F, Field, CA, 2008, Families in Ireland:An analysis of Ppatterns and trends, Dublin: Stationery Office.

Gray,J, Rooney, C, 2018, Supporting low income working families: Enabling resilience, MUSSI (Maynooth University Social Sciences Institute) Working Paper No 2, Maynooth: Maynooth University Social Sciences Institute

Hannes, K, Lockwood, C, 2012, Synthesising Qualitative Research: Choosing the Right Approach, Chichester: Wiley Blackwell

Haux, T, 2010,Activating lone parents:Applying alternative approaches to the British case, 6th International Policy and Research Conference on Social Security, Luxembourg

Henderson, DA, Tickamyer,AR, Tadlock, BL, 2005, The impact of welfare reform on the parenting role of women in rural communities, Journal of Children and Poverty $11,2,131-147$

Hick, R, 2018, Enter the Troika:The politics of social security during Ireland's bailout, Journal of Social Policy 47, 1, 1-20 
Houses of the Oireachtas, 2017, Report of the Joint Committee on Social Protection: Report on the Position of Lone-parents in Ireland, Dublin: Houses of the Oireachtas, http://data.oireachtas.ie/ie/oireachtas/committee/dail/32/ joint_committee_on_social_protection/reports/2017/2017-06-15_report-on-theposition-of-lone-parents-in-ireland_en.pdf

Indecon, 2017, Indecon Independent Review of the Amendments to the One Parent Family Payment since 2012, Dublin: Indecon

Lacroix, G, Brouillette, D, 2011,Assessing the impact of a wage subsidy for single parents on social assistance, Canadian Journal of Economics/Revue Canadienne d'économique, 44, 4, 1195-1221

McGinnity, F, Russell, H, Watson, D, Kingston, G, Kelly, E, 2014, Winners and Losers? The Equality Impact of the Great Recession in Ireland, Dublin: Economic and Social Research Institute

McMullin, J, Davies, L, Cassidy, G. 2002, Welfare reform in Ontario:Tough times in mothers' lives, Canadian Public Policy/Analyse de Politiques, 28, 2, 297-314

Manoogian, MM, Jurich, J, Sano, Y, Ko, J, 2015, My kids are more important than money: Parenting expectations and commitment among Appalachian low-income mothers, Journal of Family Issues 36, 3, 326-350

Millar,J, 2008, Making work pay, making tax credits work:An assessment with specific reference to lone-parent employment, International Social Security Review 61, 2, 21-38

Millar, J, 2011, Tax credits: A close-up view, Journal of Poverty and Social Justice 19, 1, $39-50$

Millar, M, Crosse, R, 2016, Lone Parents and Activation, What Works and Why: A Review of the International Evidence in the Irish Context, Galway: UNESCO Child and Family Research Centre NUI Galway

Millar, M, Crosse, R, 2018, Lone parent activation in Ireland: Putting the cart before the horses?, Social Policy and Administration 52,1,111-129

Murphy, M, 2012, Careless to Careful Activation, Dublin: National Women's Council of Ireland

Noblit, GW, Hare, RD, 1988, Metaethnography: Synthesizing Qualitative Studies, London: Sage

One Family, 2015, OFP reforms:The real-life impacts, 23 July, https://onefamily.ie/ policy-ofp-reform-real-life-impacts/

Patterson, L, 2008, The limits of work-activation: New Zealand lone mothers' income adequacy, security, and sustainability over time, International Symposium Lone Mothers and Welfare to Work Policies, Vancouver, BC, Canada: Simon Fraser University

Ray, K, Vegeris, S, Brooks, S, Campbell-Barr, V, Hoggart, L, Mackinnon, K, Shutes, I, 2007, The Lone Parents' Pilots: A Qualitative Evaluation of Quarterly Work Focused Interviews (12+), Work Search Premium \& In Work Credit, Sheffield: Department for Work \& Pensions

Ring, N, Ritchie, K, Mandava, L, Jepson, R, 2010, A Guide to Synthesising Qualitative Research for Researchers Undertaking Health Technology Assessments and Systematic Reviews, NHS Quality Improvement Scotland, www.nhshealthquality.org/ nhsqis/8837.html

Rowlingson, K, Millar, J, 2002, Lone parents, poverty and work: Policy approaches and lessons from aboard, Benefits 10, 3, 207-213

Savage, M, Callan, T, Regan, M, Walsh, JR, 2017, Supporting Family Incomes: Getting the Balance Right, Dublin: Economic and Social Research Institute 
Verbist, G, Roggerman,A, De Lathouwer, L, 2007, Labour market activation policies: A comparison of the use of tax credits in Belgium, the UK \& the US, in JD Koning (ed) The Evaluation of Active Labour Market Policies: Measures, Public Private Partnerships \& Benchmarking, Cheltenham: Edward Elgar.

Watson, D, Lunn, P, Quinn, E, Russell, H, 2011, Multiple Disadvantage in Ireland: An Equality Analysis of Census 2006, Dublin: Economic and Social Research Institute 